\title{
Framework for soft and hard city infrastructures
}

Mark Dyer DPhil, FICE, CEng

Professor, University of Waikato, Hamilton, New Zealand

(corresponding author: mdyer@waikato.ac.nz)

(Orcid:0000-0002-6766-0893)

Rachel Dyer BA, MSC

Planning Officer, Hamilton City Council, Hamilton, New Zealand

Min-Hsien Weng PhD

Senior Research Fellow, University of Waikato, Hamilton, New Zealand

Shaoqun Wu PhD

Lecturer in Computer Science, University of Waikato, Hamilton, New Zealand

\author{
Thomas Grey BArch, MSc \\ Senior Research Fellow, Trinity College Dublin, Dublin, Ireland \\ Richard Gleeson BA, MSC \\ Retired Dublin City Planner, Trinity College Dublin, Dublin, Ireland \\ Tomás García Ferrari \\ Senior Lecturer in Graphical Design, University of Waikato, Hamilton, \\ New Zealand
}

The term city infrastructures is often restricted to the physical elements of a city, while in practice it comprises both hard infrastructures for built environment and utilities, as well as soft infrastructures involving services, social groupings and personal skills. Part of the confusion is the lack of clarity about the role and delivery of city infrastructures and its relationship to livelihood and livability. To address this issue, a framework for soft and hard city infrastructures has been developed using results from two case studies to model the relationships, conflicts and connections between soft and hard infrastructures. The first case study concerns the abandonment of a planned urban regeneration project for the Italian City of Lucca in Tuscany where institutional inertia prevented regeneration of a derelict tobacco factory. The second case study concerned results from data analysis of contributions for a public consultation exercise for City of Christchurch in New Zealand. The syntactic data analytics using Flax software coupled with data visualisation demonstrated how an urban narrative can be constructed about citizen priorities based on a framework for soft and hard city infrastructures. The methodology enables citizen engagement through cultivating open processes of urban exploration that advocate 'connected infrastructures' thinking.

\section{Introduction}

The design, construction and maintenance of the physical fabric of cities is strongly influenced by town planners, architects and engineers based on their professional judgement with often minimal input from the people living and working in these urban spaces. This detached relationship between the professional expert, and the citizen as a primary user, is further complicated by the scarcity of scientific objective research into how city infrastructures actually perform and in particular meets the needs of users. This situation is due in part because design practice and scientific research occupy 'two very different worlds' where design is more intuition led rather than evidence based on tools such as post occupancy evaluation whereas the cornerstone of scientific research is objectivity (Dyer et al., 2017; Nisha and Nelson, 2014).

At the same time, the term city infrastructures is often restricted to the physical elements of a city, while in practice it comprises the rich ecology of utilities, services, land ownership, networks, social groupings and personal skills. Furthermore, decision making about urban development is not a level playing field with many citizens and communities denied meaningful access to decision making. Part of the reason is the lack of clarity about the role and delivery of infrastructure, and the relationship to livelihood and liveability.

To deal with these shortcomings, a framework for soft and hard city infrastructures has been developed to explore the symbiotic relationship between these two facets of urban living. The methodology is geared towards enabling citizen engagement through cultivating open processes of urban exploration, and advocating the need for 'connected infrastructure' thinking (as opposed to disconnected infrastructures). As such it aims to create the capacity among citizen and stakeholder groups to critique infrastructural provision and participate in strategic design thinking about how urban qualities are under-pinned by connected infrastructures, which can strengthen resilience and increase sustainable governance as we face an uncertain global future.

\section{Framework for soft and hard city infrastructures}

\subsection{Cities as complex systems}

By their very nature, cities are complex systems. Back in the 1960's, Jane Jacobs was a leading advocate for seeing the city 
as a living organism that thrived on diversity where mixed use neighbourhoods support greater liveability and livelihood (Jacobs, 1961). Furthermore, Vale and Vale (1991) describe the city as dynamic interactive systems that demand systems thinking in order to unpick the many challenges. Likewise, the systems approach has informed the work of Newman and Jennings (2008) who promoted the 'cities as sustainable ecosystems'. This approach, which focuses on relationships and processes, gives a better insight into emergence and complexity; while also acknowledging the importance of context where 'Ecosystems are nested, as we are nested within ecosystems - systems within systems, wholes within wholes'. It was argued that cities will be more sustainable if they reflect the ecological principles that operate within natural systems.

In light of the challenges facing the creation of sustainable urban ecosystems, urban spatial planning has come under pressure due to greater urbanisation, and recognition that cities must be considered as complex adaptive systems. According to Albrechts (2006) urban development issues call for a holistic planning approach, where strategic spatial planning is 'selective', rather than trying to solve all problems at once. It is 'relational-inclusive' with a focus on relations and processes while being inclusive of many stakeholders. Strategic spatial planning can then be thought of as being 'integrative' in that it brings vertical and horizontal integration between institutional processes. This outlook is based on 'Visioning' with creative thinking about possible and desirable futures for a place; while finally strategic spatial planning being 'action oriented' where the focus is on implementation and getting things done. This emphasis on implementation prioritises connections between various authorities, institutions, private organisations, community groups and individual citizens. However, many authors in this area acknowledge that the implementation of strategic spatial planning is undermined by a lack of political will, existing patterns of technocratic planning, land ownership and the inability of many actors (politicians, planners, community bodies or private organisations, citizens etc.) to grasp or engage with alternative, more collaborative forms of planning (Healey, 2004, 2006). Likewise, Newman (2008) was not surprised that strategic spatial planning has not taken hold to any significant degree. This alterative form of planning demands 'imaginative actors to help forge new forms of collective action' but such collective action, which seeks to bring government and civil society together, is frequently undermined as these actors often have contradictory views.

\subsection{Framework for soft and hard city infrastructures}

Given the difficulties facing the implementation of strategic spatial planning and the need to bridge the perennial gap between top-down and bottom-up approaches as documented by others (Campbell and Cowan, 2015; EC-EIP, 2013; Murray et al., 2009; OECD, 2001a; OECD, 2001b; Pissourios, 2014) a framework for city infrastructure is proposed based on the interrelationship between hard and soft city infrastructures as illustrated in Figure 1. It represents city infrastructures as a matrix of soft and hard infrastructures within formal and informal settings that are ultimately intended to support liveability and livelihood for people and communities living, working and visiting cities. These infrastructures do not represent actual conditions within a community. As such it is a framework that can be employed to examine the key support systems within a community that influence a range of social, environmental and economical urban issues such as mobility, quality of urban space, provision of community services and so on.

In particular, the framework describes three hard infrastructures as follows.

Utilities: Utilities refer to physical services such as transportation, water and waste systems, information and communications technology (ICT) and so on. These utilities connect and operate equally across all urban scales, including national and international interconnectivity.

Urban space: Urban space is considered largely as bounded space, in the form of streets, urban plazas or local squares, playgrounds, parks and so on. Urban space is typically identifiable at the neighbourhood scale or district scale, depending on the nature of the open space and pattern of land ownership.

Buildings: The building infrastructure refers largely to architectural space defined as single or grouped buildings forming part of an urban block. This will include dwellings, educational buildings, healthcare buildings and so on.

By their nature, soft infrastructures are harder to define or map onto specific spatial scales. However, referring to previous studies by Landry (2006), Tonkiss (2014) and Casey (2005), three primary soft infrastructures can be defined as follows.

Institutional: Institutional infrastructures refer to public and private systems which provide certain services within the city such as local government, healthcare services or educational services. It may also include sporting, art and culture or official community support organisations. These institutions are typically top down and more formal in nature.

Communal: Community infrastructures refer to informal networks or community groups that occur within neighbourhoods or districts. These infrastructures rely on bridging and linking social capital. While 'Communities of Interest' or online communities may not be location specific, many community organisations will relate to a specific physical community delineated 


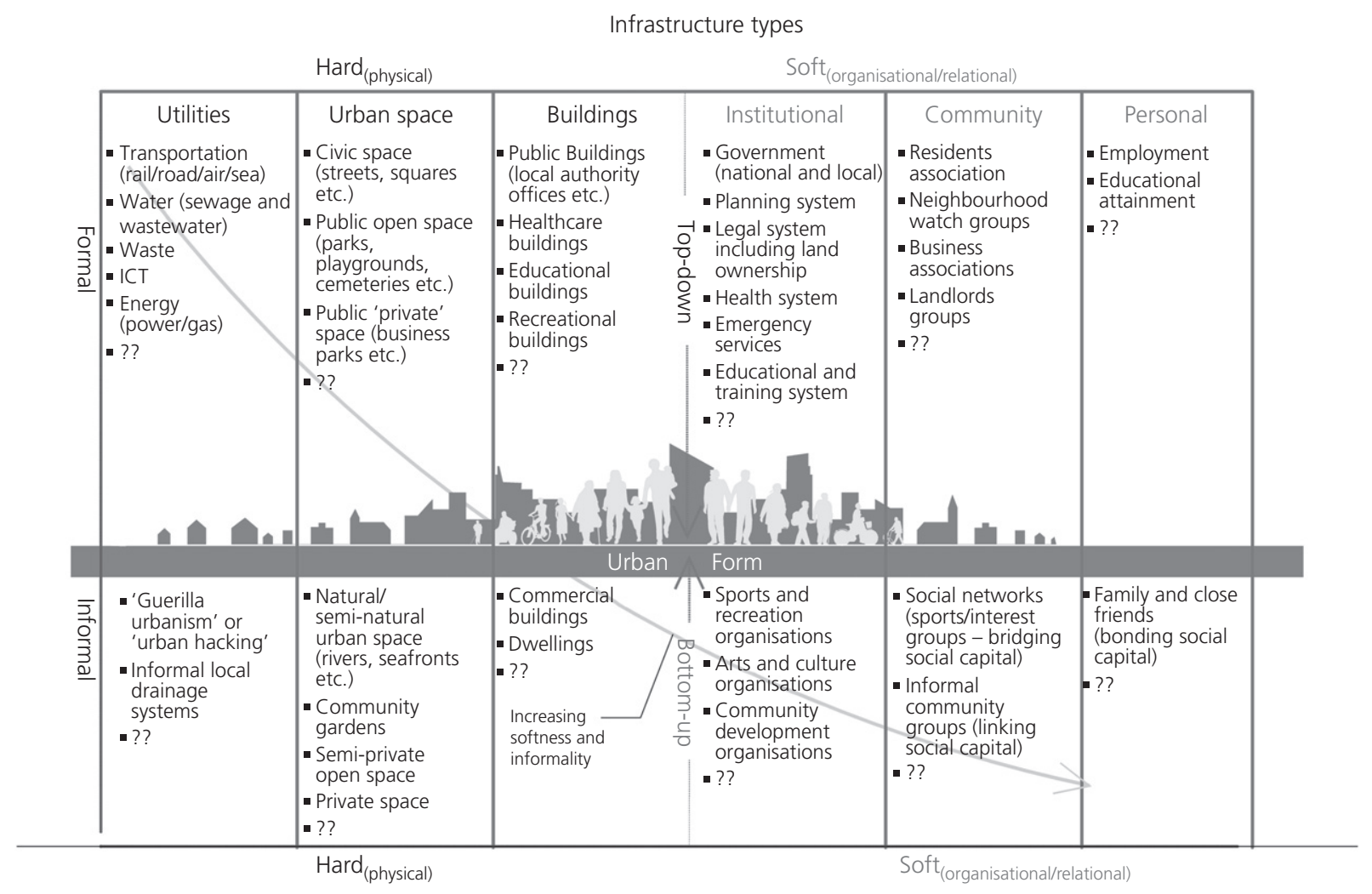

Figure 1. Framework for soft and hard city infrastructures

by political, parish or physical boundaries (a river, large street etc.). In this regard, community infrastructures will often operate within the district scale and arguably at a more identifiable level at the neighbourhood scale.

Personal: Personal infrastructure refers to the support systems a person will have at an individual, family or friendship level. This will often involve bonding social capital where membership of a family or social group is critical to a sense of belonging. It will also include educational attainment and other support systems that occur at an individual level.

One of the most significant characteristics of modern society is the ease, speed and inexpensive movement of people and information. The evolution of transport and ICT means that people can commute great distances or communicate and maintain personal, business, educational or recreational relationships regardless of geographic location. In this context, the framework is seen as a starting point and there may be other infrastructures worth including. However, the six infrastructures currently outlined will characterise many issues within a community across social, environmental and economic domains. It is also important to recognise that these

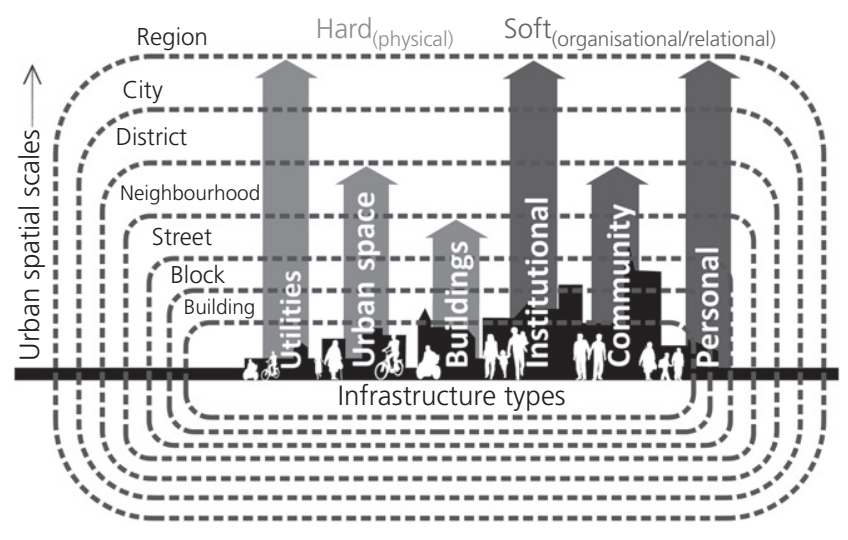

Figure 2. Sample spatial distribution of soft and hard city infrastructures

infrastructures can and will overlap and intertwine across the city and at different scales as illustrated in Figure 2.

In fact, the relationship between city infrastructures and spatial scale provides a valuable framework for understanding how 
different stakeholders might collect and map data in the urban environment. Furthermore, it helps structure how stakeholders might present and interpret data to support community participation and collaborative urbanism. For example, when collecting data from stakeholders, Moughtin et al. (2005) contend that public engagement is most effective at the city quarter, or neighbourhood level, as these represent a scale where residents can contribute their local knowledge and expertise. This is because neighbourhoods, quarters or districts of the city have a somewhat identifiable boundary, recognisable to both residents and outsiders alike. These neighbourhoods are structuring elements which are common to most cities and act on people's perception of the city, thus making the urban environment more intelligible and legible (Lynch, 1960). In addition, most people interact with the urban environment on a daily basis at the neighbourhood scale, and therefore this scale has a significant impact on their quality of life.

As such the framework of city infrastructures provides a useful model for collecting and mapping data within a community in relation to specific issues such as transport or housing. The cities infrastructures approach has the advantage of ensuring that no major component is being ignored in terms of data collection, analysis or proposed intervention. For example, a combination of local authority documentation and traditional on street audits will reveal a great deal about hard infrastructure such as utilities or open space, but little about community and personal infrastructures. As a consequence, alterative datagathering tools such as questionnaires or crowdsourcing community data can be collected to compare and contrast hard and soft infrastructures.

\section{Case study for city of Lucca, Italy}

The framework for city infrastructures was tested at the Italian Renaissance city of Lucca in Tuscany as illustrated by the historic map in Figure 3. The study investigated the demise of the so-called integrated plan for sustainable urban development (PIUSS) regeneration project for the former Toscana Cigar factory and the barriers to its progression. The PIUSS project had been granted EU Structural Funds, 24 million, plus an additional 16 million euro to be provided from the region/province/city, to regenerate derelict land in one corner of the historic city that had been transferred to public ownership. The PIUSS project was expected to implement a number of interventions, both public and private urban developments aimed towards economic development. In particular, the PIUSS project was intended to address the following issues.

(a) Physical infrastructure. Urban decline: Parts of the city are in serious decline. For example, only a few metres from the world heritage landscape, derelict areas exist that cannot be accessed. Furthermore, the physical infrastructure of the historic city needs to be adjusted and

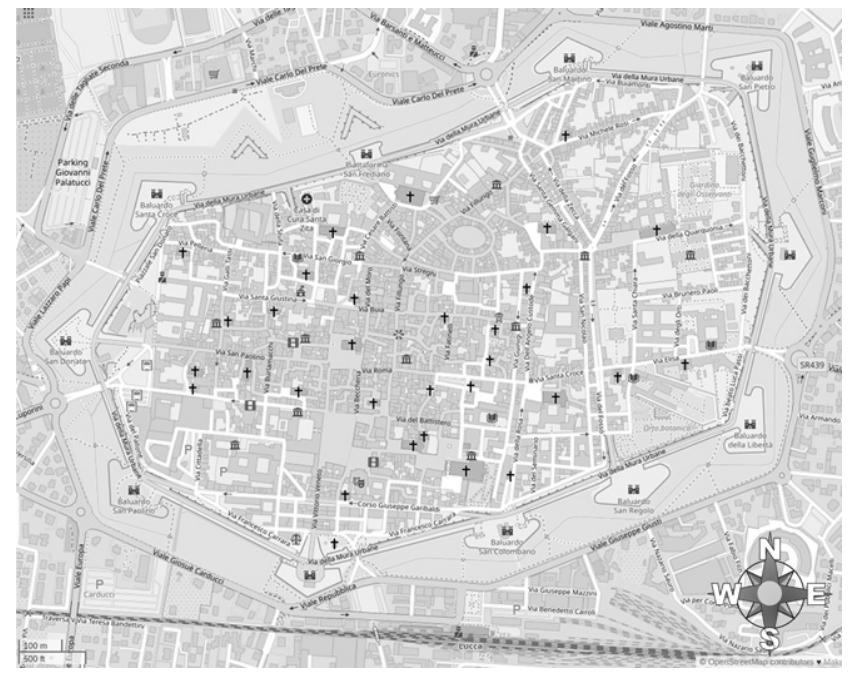

Figure 3. Historic map of Lucca (credited to '(C) OpenStreetMap contributors')

upgraded for modern needs for example mobility and sanitation which will involve a mixture of private and public land.

(b) Institutional infrastructure. Different agencies and institutions have their base outside the city/region - for example, regulatory aspects of conservation sit under the Ministry of Culture in Rome leading to fragmentation among the community of stakeholders.

(c) Communal infrastructure. Up to 60 tour buses of tourists from Pisa and Florence visit the city on a daily basis. This very short-term relationship has only a limited benefit for both the city and the visitor. Longer-term residential stays need to be promoted, relating tourism to urban identity.

(d) Communal infrastructure. There are major differences between Lucca inside the walls and Lucca outside the walls. Understanding and successfully interfacing this relationship is a major challenge.

(e) Personal infrastructure. Citizen mindset: There was a constant challenge to successfully communicate the proposed changes. Despite an extensive process of facilitated citizen engagement, some stakeholders remain quiet during consultation, yet make strong negative submissions late in the process.

To understand why the PIUSS project did not proceed, a field study was carried out over a two-week period in September 2014. The study was undertaken by an inter-disciplinary team of architects, planners, public managers, anthropologists, computer programmers and engineers. The field study identified several barriers against citizen engagement along with several 
weaknesses to the long-term sustainability of the city. These are described as follows.

(a) Disconnections between the institutional and communal infrastructures due to an overly strong diaspora, catholic community represented by 100 churches, local mercantile community that effectively disenfranchised the local citizenship from decision making for PIUSS.

(b) Disconnections between the physical infrastructures of the historic core and surrounding modern suburbs characterised by the presence of a massive intact historic city wall and green belt with limited physical access.

(c) Disconnections between the communal infrastructures of historic core and surrounding suburb caused by dominant Airbnb tourist rental sector within the city walls together with a significant daily influx of tourist buses.

(d) Disconnections within the physical infrastructure for surrounding modern suburbs due to railway line bisecting the suburbs with a single bridge crossing together with past destruction of an historic Roman aqueduct to accommodate a modern highway.

(e) Disconnections between the commercial community and educational community where no tertiary educational institutional existed to promote education and research into the conservation of historic physical infrastructure that could upskill local population and support personal infrastructure.

( $f$ ) Unwillingness to recognise the potential for district cooling from the underground network of caves beneath the historic city.

In essence, the city infrastructure framework highlighted major disconnections between several forms of soft and hard city infrastructures that weakened urban governance and by their very nature presented significant obstacles to the successful implementation of the PIUSS project.

\section{Case study for city of Christchurch, New Zealand}

The framework for city infrastructures was tested for Christchurch City Council, New Zealand. In particular, the city infrastructure framework was used to interpret data from the post-earthquake public consultation titled 'Share an Idea'. Although the full dataset was not available for ethical reasons, the study used a subset of 1000 stories documented in a report titled 'Common Themes' authored by Christchurch City Council (2011).

Using linguistic software Flax developed by $\mathrm{Wu}$ and Witten (2015), syntactic analysis was undertaken to identify the collocations of two or more consecutive words that appear more frequently than random events. For instance, the phrase 'shuttle bus' could be identified in a sentence as an example of high-frequent word combinations that indicate high trending topics of interest to people. Using this approach, the syntactic analysis used a combination of 'noun+noun' to identify different categories of soft and hard infrastructure while a combination of 'adjective+noun' was used to explore the different qualities or attributes desired of city infrastructures such as safety, economics, accessibility or conveniences. A selection of collocated terms identified by Flax is shown in Figure 4.

In particular, the 'noun+noun' collocations describing different sub-categories of city infrastructure was encoded as a structured $\mathrm{xml}$ to show the words ('text' element), usage frequency ('fre' attribute value) and part-of-speech tag ('tagged_text' element) as illustrated in Figure 4(a). For example, the term 'car parks' appears 8 times in all story contexts, and the word 'car' is tagged as a singular noun and 'parks' as a plural noun. Each infrastructure sub-category was mapped as being either hard or soft infrastructures. Hard infrastructure categories include 'utilities', 'public space' and 'building', and soft infrastructures comprise 'institutional', 'community' and 'personal. In this case, 'bus exchange' and 'car parks' are associated with 'public space' infrastructure while 'transport options' are assigned to 'utilities'. Likewise, collocation patterns of 'adjective+noun' that described the quality of urban infrastructures were encoded as an $\mathrm{xml}$ document where the adjective is denoted as ' $\mathbf{J}$ '. For example, in the phrase 'light rail' in Figure 4(b), the term 'rail' belongs to the 'utilities' hard infrastructure category, and the adjective 'green' describes the quality associated with the infrastructure sub-category.

Having encoded collocation patterns, JavaScript software from D3.js was used to generate chord diagrams that illustrated connections between soft and hard city infrastructures. Furthermore, software MarkJS ('mark.js - JavaScript keyword highlight', n.d.) was used to highlight the key words used to identify different sub-categories and characteristics of hard and soft city infrastructures. The graphical results are illustrated in Figure 5. The data visualisation indicated 'public space' as the hard city infrastructure that attracted the greatest attention and by default the highest number of connections with other categories of soft and hard city infrastructures. This preliminary outcome indicates public space as top trending topic for residents of Christchurch and should be a priority for future development of the city centre of Christchurch.

Furthermore, the linguistic analysis allowed individual terms for collocated words to be highlighted in text for individual stories as shown by the screen shot presented in Figure 6. Here, the original text is presented for an individual story from the public consultation exercise that connects the two city infrastructure categories of 'Public Space' with 'Community', 


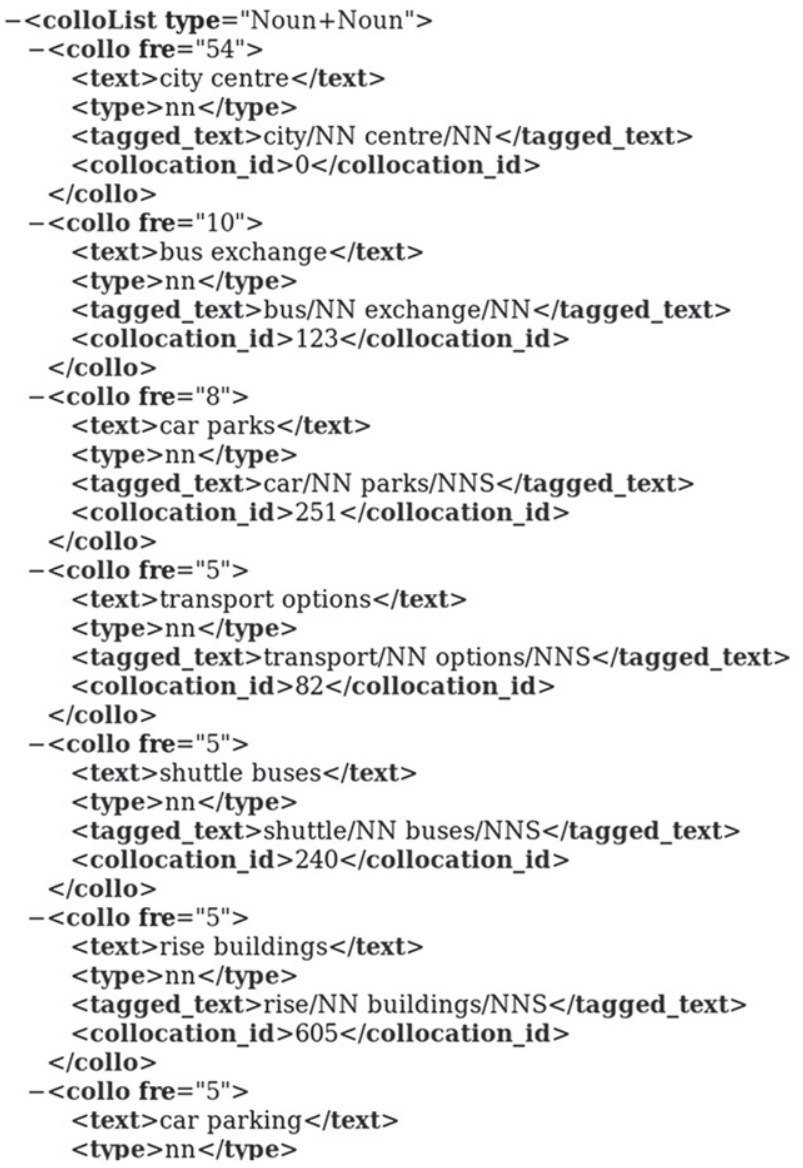

(a)

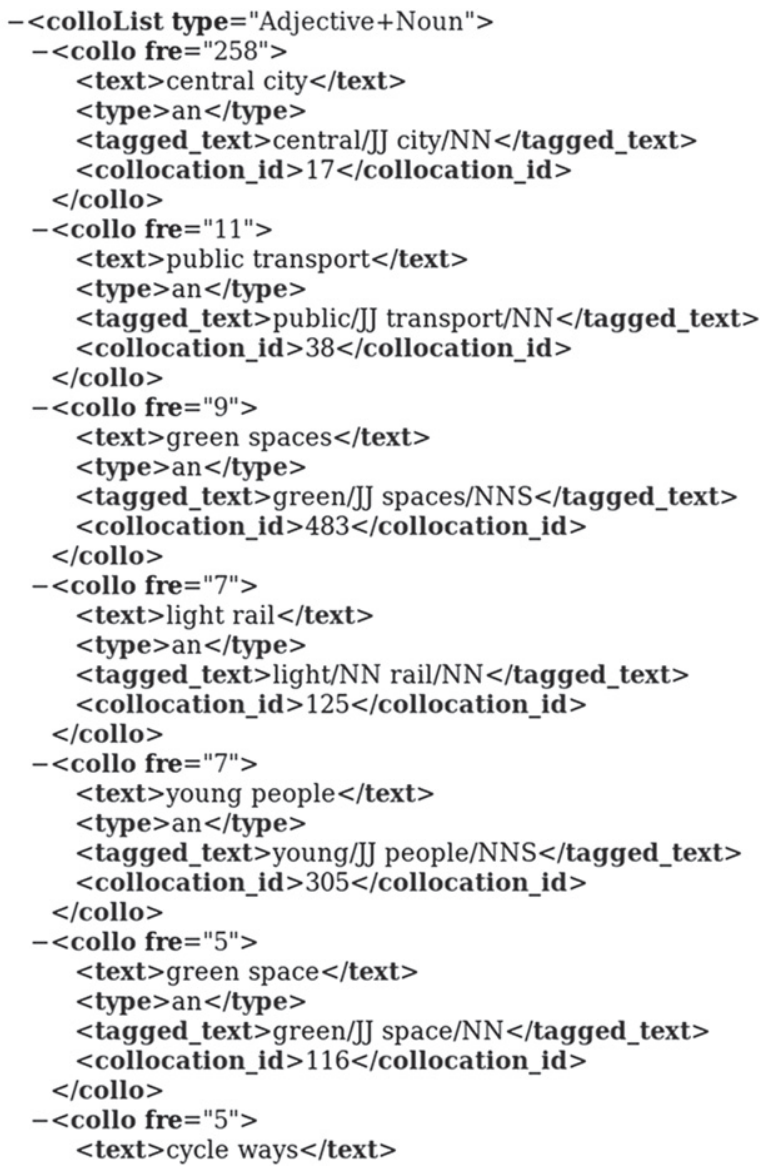

(b)

Figure 4. (a) Sub-categories of urban infrastructure, (b) qualities of urban infrastructure

respectively. The individual terms referring to the two city infrastructure categories are highlighted in boxes and the desired characteristics are shown in bold text. In this case, the contributor is concerned about affordable convenient transport options to access the city centre. Interestingly, many of the contributions from the public consultation exercise were either concerned about transportation or safety.

The study was extended further by comparing the qualitative data from syntactic analysis of public consultation data with quantitative municipal data (Christchurch 2011). The result is a collage illustrated in Figure 7 that represents a visual data story for long-term strategic planning. Here, the statistical municipal data were used to calibrate the qualitative data. For example, even though public transport was identified as a highly trending topic in the public consultation exercise, the statistical data showed that only $3.7 \%$ of people in Christchurch used public transport compared with $20 \cdot 4 \%$ in Wellington city. This does not mean that residents were uninterested in using public transport but it does highlight a disconnect between wanting affordable public transport and a current low usage which may be connected to low density suburban housing but nevertheless indicates a desire for public or semi-public transportation possibly facilitated through the gig-economy. In a different vein, the importance attributed to beautiful buildings in text analysis coincided with statistical data showing $64 \%$ of respondents satisfied with a look and feel of new buildings in Christchurch city centre.

In summary, the pilot study showed the importance of calibrating qualitative data from syntactic analysis of public stories with quantitative statistical data. At the same time, the qualitative data enable a narrative to be constructed about the type of city infrastructures desired by residents that connect soft elements of a city (people, communities, institutions) with the hard elements (roads, transportation systems, buildings, public spaces) to improve livability and livelihood. 


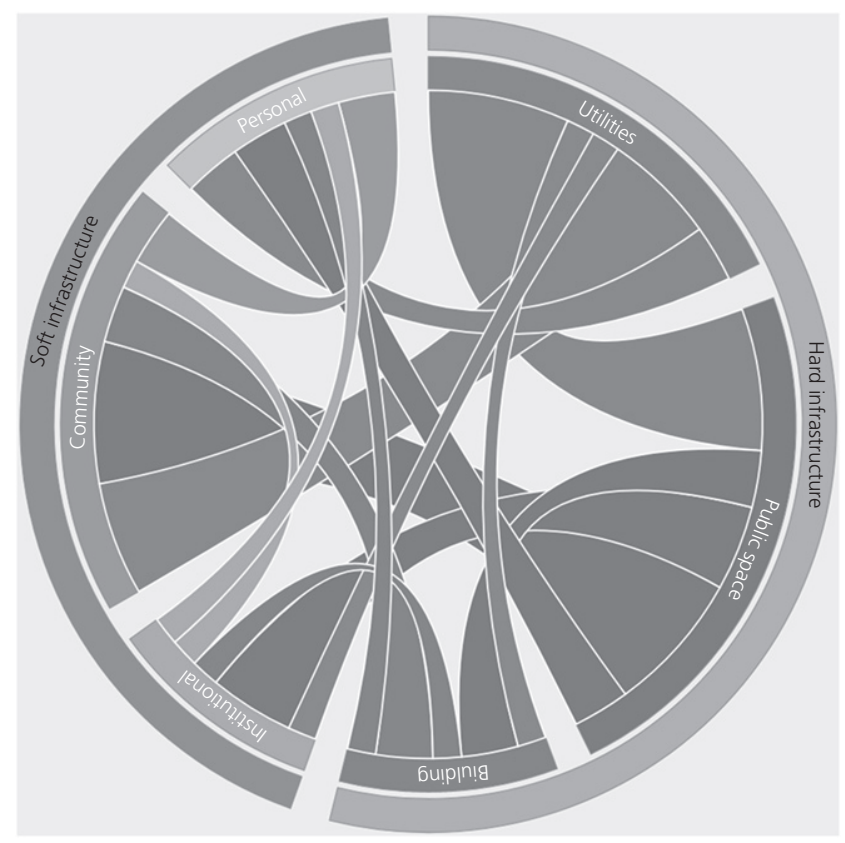

Figure 5. Data visualisation of relationships between soft and hard city infrastructures identified from Syntactic Analysis of 300 Stories from Christchurch 2011 Post-Earthquake Public Consultation

\section{Disconnections between soft and hard infrastructures}

The two case studies highlighted the benefits of interpreting data and information about towns and cities in relation to soft and hard infrastructures in order to better understand the disconnections that can lead to the full potential for increased livelihood and livability not being fully realised in urban environments. These disconnections goes to the heart of how towns and cities are often governed formally or informally which in turn translates into physical hard infrastructure constructed by architects, engineers and planners to meet the specific social, political, economic and environmental goals. Sometimes the mismatch is caused by competing interests between different institutional systems and organisations for the provision of hard infrastructures at different scales in relation to transport, energy, water, health and education. The case study for Lucca illustrates disconnections very well. In this case, the absence of a political consensus in tune with community groups led to inaction and a return of a significant unspent regional development grant. The result was ongoing dereliction in an otherwise beautiful UNESCO Heritage city visited by $10000 \mathrm{~s}$ tourist annually. Yet the derelict quarter had the potential to fill the void of a tertiary educational institute within the city's soft and hard infrastructures and so provide necessary skills to maintain and conserve the

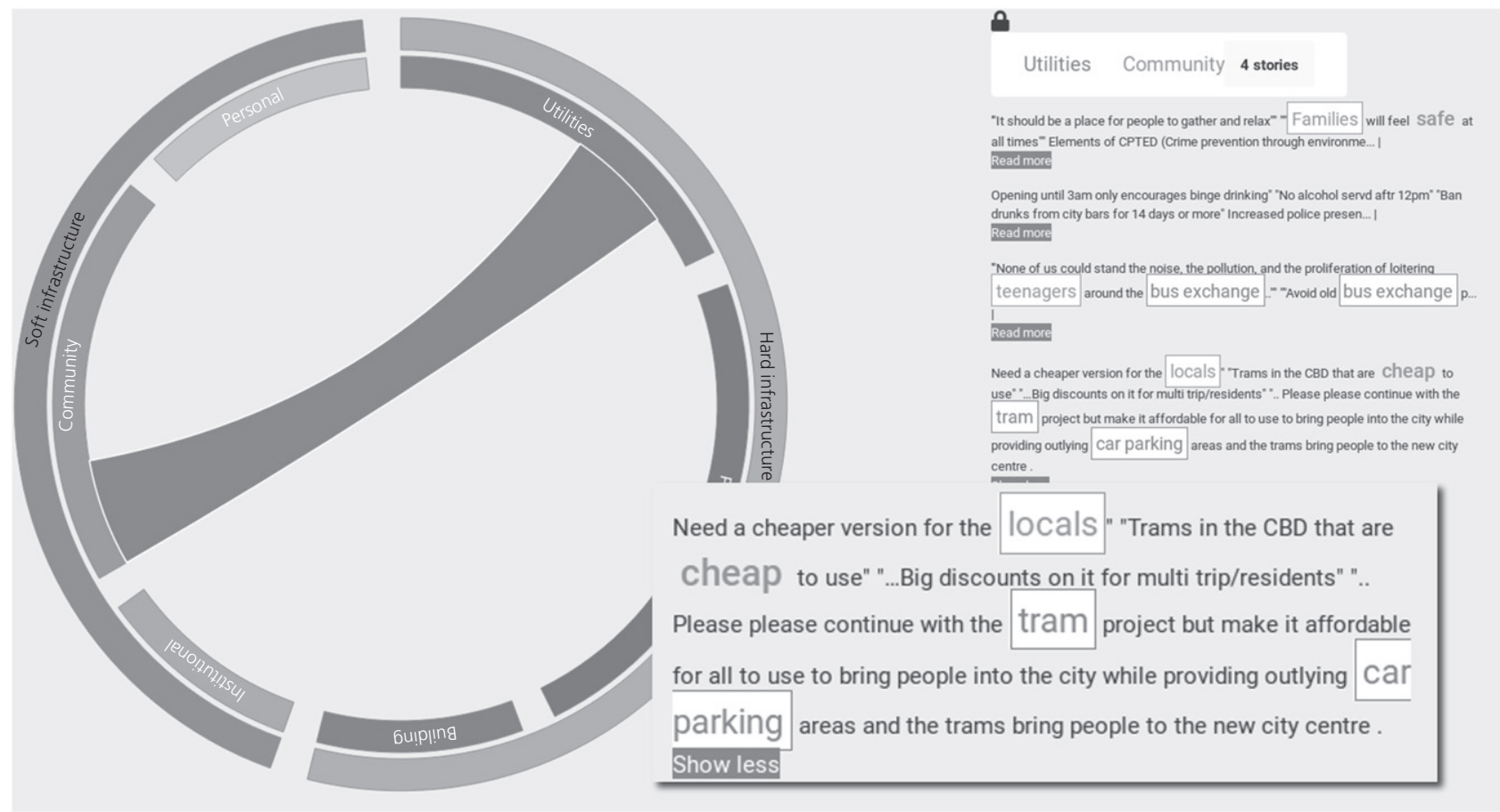

Figure 6. Data visualisation and original text for individual stories connecting 'utilities' with 'community' (City Infrastructures from Christchurch 2011 Post-Earthquake Public Consultation) 


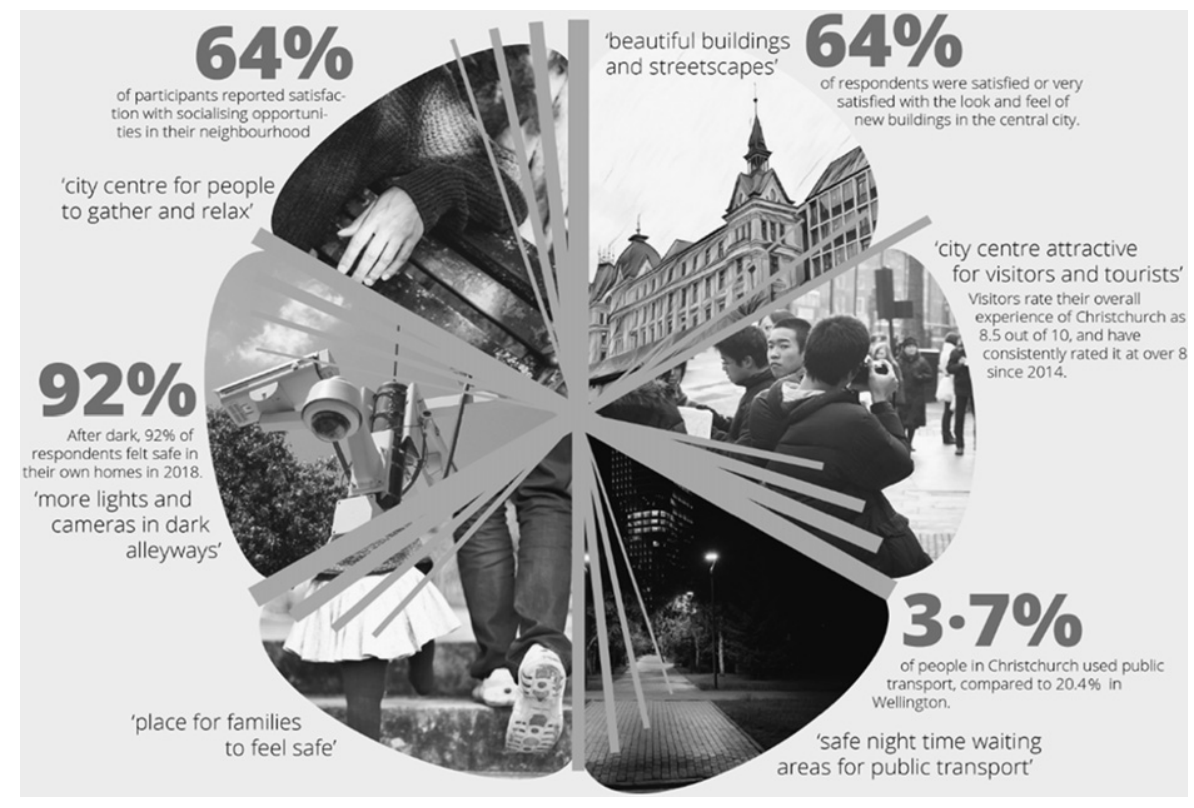

Figure 7. Urban narrative based on integration of bottom-up qualitative data from Flax syntactic analysis and top-down quantitative municipal data for Christchurch city, New Zealand (Christchurch City Council (2019))

historic urban fabric. Likewise but in a different vein, the results for Christchurch highlighted disconnects between an apparent public interest for affordable public transport with relatively low take-up levels in practice without a clear explanation. Both cases illustrated that the disconnections between soft and hard infrastructures are often a reflection of disconnections between top-down and bottom-up urban governance processes. This is not a new finding. The bibliometric study by Dyer et al. (2017) of 14850 publications on Web of Science reveal a similar chasm between research published into urban governance compared with urban design and planning. The study showed that peer-reviewed publications into urban governance and urban design was mutually exclusive with a very few notable exceptions. Likewise, the importance of political consensus to connect soft and hard infrastructures was well illustrated by the ethnographic studies undertaken by Dyer and Ogmundardottir (2018) of the two Scandinavian cities of Vaxjo and Sonderborg. Based on a common narrative constructed around environmental protection an urban symbiosis was created between soft and hard infrastructures in terms of educational, health and well, agricultural organisations with utilities and buildings that transcended the political cycle. In comparison, the Municipality of Sonderborg created similar urban symbiosis centred on job creation that connected local business and local government infrastructures with retrofitting and renewable of the building stock and energy utilities system to promote a low carbon community.

\section{Conclusions}

In conclusion, the proposed framework for soft and hard city infrastructures has been tested on case study data for two distinctly different cities. In the case of Lucca, the framework helped understand how a regeneration project for a derelict quarter of the historic city had been abandoned due to weakness and inertia with the institutional component of the soft city infrastructures for Lucca. This in turn had the potential to impact on the long-term conservation of physical fabric of the historic city, which was showing obvious signs of neglect and decay. At the time, this made uncomfortable reading for the political and business leaders of Lucca. As a solution, the framework for city infrastructures pointed to the benefits of redeveloping the derelict quarter into an educational and research institute to enhance both institutional infrastructure of Lucca. The educational and research institute would provide training and expertise in building conservation, which would strengthen the personal infrastructure for residents of Lucca and offer alternative means of livelihood beyond the hospitality sector for tourism.

In comparison, the case study for Christchurch demonstrated the capacity of using Flax software to interrogate large amounts of text data from a bottom-up consultation exercise post-earthquake. The software used syntactic analysis to detect collocation of nouns and nouns or nouns and adjectives. Using a glossary of terms, the collocation of noun plus noun revealed residents' thoughts about perceived relationships between different categories of soft and hard city infrastructures. While, collocation 
of nouns and adjectives indicated the qualities of city infrastructures expected by residents such as safer public spaces or more economic public transport. This linguistic data analysis was in turn plotted using chord diagrams to visualise relationships perceived between different categories of soft and hard city infrastructure. A facility was added to the chord diagrams to extract individual contributions or 'stories' from residents with highlight text for different elements of soft and hard city infrastructure. To check the validity of the qualitative data from public consultation exercise, a comparison was made with quantitative municipal statistical data on topic areas ranging from public transport, streetscape, safety and tourism. Perhaps not surprisingly, there was both agreement and disagreement between the two data sets which at the very least starts a dialogue between bottom- and top-down processes for collaborative urban planning and design to support liveability and livelihood.

\section{Acknowledgements}

The Lucca field study was supported by EU COST Acton TU1204 People Friendly Cities in a Data Rich World. The Christchurch case study was supported by New Zealand National Scientific Challenge for Better Built Homes, Towns and Cities. The City Infrastructure model was sponsored by Enterprise Ireland.

\section{REFERENCES}

Albrechts. L (2006) Shifts in strategic spatial planning? Some evidence from Europe and Australia. Environment and Planning $A$ 38: 1149-1170.

Campbell K and Cowan R (2015) Massive small compendium (sample of upcoming publication). Urban Exchange.

Casey S (2005) Establishing Standards for Social Infrastructure. University of Queensland, Queensland, Australia.

Christchurch City Council (2011) Common Themes. Christchurch City Council, New Zealand.

Christchurch City Council (2019) Facts, Stats and Figures. Christchurch City Council, New Zealand. See https://www.ccc.govt.nz/cultureand-community/christchurch/statistics-and-facts/facts-stats-andfigures/ (accessed 11/04/2019).

Dyer M and Ogmundardottir H (2018) Ethnographic study of community participation in transition towards a fossil fuel economy at Vaxjo and Sonderborg. ICE Proceedings Energy, London, UK.

Dyer M, Chiara C and Corsini F (2017) Making urban design a public participatory goal: explorations towards evidence-based. ICE Proceedings Urban Design and Planning, London, UK.

EC-EIP (European Commission-European Innovation Partnership) (2013) European innovation partnership on smart cities and communities - strategic implementation plan. In (European Commission (ed.)), Brussels, Belgium.

Healey $\mathrm{P}$ (2004) The treatment of space and place in the new strategic spatial planning in Europe. International Journal of Urban and Regional Research 28(1): 45-67.

Healey P (2006) Urban Complexity and Spatial Strategies: Towards a Relational Planning for our Times. Taylor and Francis, London, UK. See https://doi.org/10.1080/01944360701755584

Jacobs J (1961) The Death and Life of Great American Cities. Modern Library, New York, NY, USA.
Landry C (2006) The art of City-Making. Earthscan, London, UK. Lynch KA (1960) The Image of the City. MIT press, Cambridge,

MA, USA.

Moughtin JC and Shirley P (2005) Urban design green dimensions [Online]. Elsevier, Burlington, VT, USA. See http://public.eblib. com/EBLPublic/PublicView.do?ptiID=269926.

Murray M, Greer J, Houston D, Mckay S and Murtagh M (2009) Bridging top down and bottom up: modelling community preferences for a dispersed rural settlement pattern. European Planning Studies 17(3): 441-462.

Newman P (2008) Strategic spatial planning: collective action and moments of opportunity. European Planning Studies 16(10): 1371-1383.

Newman P and Jennings I (2008) Cities as Sustainable Ecosystems: Principles and Practices. Island Press, Washington, DC, USA.

Nisha B and Nelson N (2014) Making a case for evidence-informed decision making for participatory urban design. Urban Design International 17(4): 336-348.

OECD (Organisation for Economic Co-operation and Development) (2001a) Citizens as Partners: OECD Handbook on Information, Consultation and Public Participation in Policy-Making. OECD Publishing, Paris, France.

OECD (2001b) Citizens as Partners: Information, Consultation and Public Participation in Policy. OECD Publishing, Paris, France.

Pissourios IA (2014) Top-down and bottom-up urban and regional planning: towards a framework for the use of planning standards. European Spatial Research and Policy 21(1): 83-99.

Tonkiss F (2014) Cities by Design: The Social Life of Urban Form. Wiley, London, UK.

Vale B and Vale R (1991) Green Architecture: Design for a Sustainable Future. Thames and Hudson, London, UK.

Wu S and Witten IH (2015) Using Wikipedia for language learning. University of Waikato, Hamilton, New Zealand, pp. 124-131. See https://hdl.handle.net/10289/9686.

\section{How can you contribute?}

To discuss this paper, please email up to 500 words to the editor at journals@ice.org.uk. Your contribution will be forwarded to the author(s) for a reply and, if considered appropriate by the editorial board, it will be published as discussion in a future issue of the journal.

Proceedings journals rely entirely on contributions from the civil engineering profession (and allied disciplines).

Information about how to submit your paper online is available at www.icevirtuallibrary.com/page/authors, where you will also find detailed author guidelines. 